\title{
Extraction and Quantification of Cytokinin from Ungerminated and Germinated Seeds of Sphenostylis stenocarpa (HOCHST. EX A. RICH.) Harms
}

\author{
$1 *$ SAM, SM; ${ }^{2} \mathrm{OKON}, \mathrm{IP}$ \\ ${ }^{I}$ Department of Botany, Akwa Ibom State University, Ikot Akpaden, Akwa Ibom State, Nigeria \\ Email: sundaysam@aksu.edu.ng,Tel: +2348028706841 \\ ${ }^{2}$ Department of Pharmacognosy and Natural Medicine, University of Uyo, Uyo, Nigeria
}

\begin{abstract}
Extraction and quantification of Cytokinin was carried out from ungerminated and germinated seeds of Sphenostylis stenocarpa. Cytokinin was extracted with methanol-chloroform-formic acid-water. The hormones were purified with polyvinyl pyrrolidone (PVP) column chromatography and quantified with high performance liquid chromatography (HPLC). High performance liquid chromatography analysis identified and quantified four endogenous cytokinins zeatins, trans-zeatin, isopentenyladenine, isopentenyladenosine. The ungerminated seeds of $S$. stenocarpa contain higher amount of zeatin, trans-zeatin, isopentenyladenine and isopentenyladenosine as compared with germinated seeds in all the hormone fractions. This study suggests that Cytokinin extracted from ungerminated and germinated seeds of $S$. stenocarpa could be a source of phytohormones for research and agricultural purposes.
\end{abstract}

\section{DOI: https://dx.doi.org/10.4314/jasem.v23i5.31}

Copyright: Copyright $\odot 2019$ Sam and Okon. This is an open access article distributed under the Creative Commons Attribution License (CCL), which permits unrestricted use, distribution, and reproduction in any medium, provided the original work is properly cited.

Dates: Received: 22 April 2019; Revised: 22 May 2019; Accepted 27 May 2019

Keywords: Extraction, Quantification, Cytokinin, Sphenostylis stenocarpa

Cytokinins are a class of plant hormones promoting cell division and tissue differentiation (Rijavec et al., 2009; Zhang, et al., 2010). These endogenous compounds in plant tissues are considered as both local and long distance regulatory signals for the coordination of plant development (Kudo et al., 2010), and are related to priming on water use efficiency and photosynthetic rate under conditions of salt stress (Iqbal and Ashraf, 2005). The motive of cytokinins are $\mathrm{N}^{6}$ - substituted purive derivatives. Depending on the $\mathrm{N}^{6}$-substituent, these compounds can be classified into isoprenoid, modified isoprenoid and aromatic cytokinins. Cytokinins occur as nucleotides, nucleosides, bases and as conjugates with sugars at the $3-, 7-$, or 9- position of the purine ring or at the $\mathrm{N}^{6}$ isoprenoid side chain (Mok and Mok, 2001; Sakakibara, 2006). More than 40 species of natural cytokinins have been identified in plant tissues (Hoyerova, et al., 2006). Since endogenous cytokinins concentrations are very low (less than $50 \mathrm{pmol} / \mathrm{g}$ of fresh weight) (Novak, et al, 2003), and plant tissue extracts contain complex multicomponent mixtures, exhaustive analysis of cytokinins contents is difficult. Sensitive and selective analytical tools are required for the determination of endogenous cytokinin levels in plant tissues. Levels of cytokinins are spatially and temporally regulated. Cytokinins are abundant in immature seeds (Letham, 1994). It is generally assumed that the root tip is the major site of cytokinin synthesis, but the cambium, the shoot apex, and immature seeds are also thought to synthesize cytokinins (Letham, 1994; Emery et al.,, 2000). Changes in cytokinin levels in association with plant development have been reported (Morris et al., 1993; Benkova et al., 1999; Dewitte et al., 1999; Emery et al., 2000; Yang et al., 2001; Jacqmard et al., 2002). Changes in cytokinin levels are also associated with the cell cycle, the levels being highest in the late $\mathrm{S}$ phase and during the M Phase (Redig et al., 1996b). Environmental factors also affect cytokinin levels, which are generally positively correlated with level of mineral nutrients, especially nitrogenous nutrients (Samuelson and Larrson, 1993; Takei et al., 2001b; Sakakibara and Takei, 2002), and decreased by water stress (Yang et al., 2001). The levels of active cytokinins in plants are expected to be regulated by the rates of biosynthesis, inter-conversion, transport, and degradation. Cytokinins accelerate chloroplast differentiation (Harvey et al., 1974) and stimulate chlorophyll production (Fletcher et al., 1973) in cucumber cotyledons. This response has been used as a bioassay for cytokinins (Fletcher and McCullagh, 1971a). The African yam bean (Sphenotylis stenocarpa Hochst. ex. A. Rich) is a leguminous crop belonging to the family Fabaceae, sub-family papilonoidae, tribe Phaseoleae, sub-tribe Phaseolionae and genus Sphenostylis (Okigbo, 1973; Allen and Allen, 1987). It is grown as a minor crop in mixed 
association with yam and cassava. Its current low status as a minor crop means that this crop is largely unexploited (Klu et al, 2001). The African yam bean is grown in West Africa, particularly in Cameroon, Cote d'Ivoire, Ghana, Nigeria and Togo (Porter, 1992). In Nigeria, it is found in localized areas in the southern part of Nigeria, where it is grown by peasant farmers as a security crop. It is in danger of extinction because of the high premium placed on the major legumes listed above and others such as Soya bean. The Economic importance of African yam bean is immense. Increasing population, high prices of staple food items, policy constraints on food importation are worsening the food security in developing countries where protein deficiency and malnutrition is predominant (Weaver, 1994; FAO, 1994, 2008). In order to meet the increasing gap in the provision of balanced food for the growing population of developing countries, attention is now being paid to lesser -known crops that have played major roles in the livelihoods of subsistent rural farming families (Ezeagu et al., 2002). Among these crops are African yam beans Sphenostylis stenocarpa (Hochst. ex A. Rich.) Harms and pigeon pea (Cajanus cajan L. Mill Sp.). They are grown for household consumption and for commercial purposes in Nigeria (Saka et al, 2004) despite their great potentials to meet adequate nutrition requirements. Such plants have variedly been referred to as under-exploited, under-utilized, orphan or neglected (Jaenicke et al, 2009). The nutritious seeds are delicious, and in most parts of Nigeria are often preferred over other leguminous seeds. In addition to its edible leaves and pods, the tubers can be used as cooked vegetable (Rice et al., 1986). Currently, there is no detailed research activity on abscisic acid and it implication in seed dormancy of Sphenostylis stenocarpa. Therefore, the objective of this work is to report the methanol-chloroform-formic acid-water extraction and quantification of Cytokinin from ungerminated and germinated seeds of sphenostylis stenocarpa.

\section{MATERIALS AND METHODS}

Extraction of Cytockinin: One hundred grams (100g) of powdered seeds were macerated with $300 \mathrm{ml}$ of methanol -chloroform- formic acid-water (12:5:1:2 $\mathrm{v} / \mathrm{v}$ ) for 24 hours at $4^{\circ} \mathrm{C}$ to inactivate any phosphate (Parker and Letham, 1973). It was then homogenized in the same solvent and centrifuged at 4, 000 r.p.m. for 30 minutes at $4^{\circ} \mathrm{C}$. The supernatant was kept while the pellet was extracted 3 times with methanol-waterformic acid (60:40:1 v/v) at $4^{\circ} \mathrm{C}$ for 12 hours with continous stirring. It was filtered under vacuum and with the combined filtrate and supernatant was reduced in vacuo at $35^{\circ} \mathrm{C}$ to an aqueous fraction $(10-$ $20 \mathrm{ml})$. An equal volume of ethanol: water $(1: 1 \mathrm{v} / \mathrm{v})$ was added to the aqueous fraction and adjusted to $\mathrm{pH} 3.4$ for column chromatography.

Polyvinylpyrrolidone (P.V.P) Column

Chromatography: The P.V.P. slurry was prepared as for gibberellins and abscisic acid. It was packed in a column $(60 \times 3.0 \mathrm{~cm})$ to a height of $30 \mathrm{~cm}$, and equilibrated with $0.1 \mathrm{M}$ phosphate buffer $(\mathrm{pH} 8.0)$. The extract was applied to the bed of the column and eluted with $500 \mathrm{ml}$ of the phosphate buffer. A $350 \mathrm{ml}$ fraction was collected and adjusted to $\mathrm{pH} 8.0$ and partitioned three times against ethyl acetate. The basic ethyl acetate fraction $(200 \mathrm{ml})$ obtained was reduced to dryness in vacuo and the residue dissolved in an aliquot of $35 \%$ ethanol for TLC.

The aqueous fraction obtained was adjusted to $\mathrm{pH} 2.5$ and partitioned against ethyl acetate. The resulting acidic ethyl acetate fraction $(200 \mathrm{ml})$ was partitioned with distilled water and later reduced in vacuo to about one quarter of its original volume. An excess of toluene solvent was then added to give the toluene ethyl acetate/water ternary azeotrope. This was then reduced to dryness and the residue dissolved in an aliquot of $35 \%$ ethanol for subsequent TLC. The aqueous fraction from the last partition was adjusted to $\mathrm{pH} 2.5$ and partitioned three times against n-butanol fraction $(200 \mathrm{ml})$. This was reduced to dryness and the residue was dissolved in an aliquot of $35 \%$ ethanol for TLC, bioassay and HPLC.

Thin Layer Chromatography for Cytokinins: Thin layer glass plate $(20 \mathrm{x} 20 \mathrm{~cm})$ of $0.5 \mathrm{~mm}$ thickness were prepared by using silica gel and allowed to dry at room temperature. The plates were activated at $105^{\circ} \mathrm{C}$ for 30 minutes. Cytokinins containing sample were loaded on the plate allowed to dry and then developed in an ascending manner in methanol:hexane $(50: 50 \mathrm{v} / \mathrm{v})$ to a distance of $10 \mathrm{~cm}$ from the origin. The plates were allowed to dry, heated at $105^{\circ} \mathrm{C}$ for 10 minutes and the resulting cytokinin bands were made visible under UV light at 254nm (yellow bands). The bands made visible under the UV light were marked and then scraped from the plates into aluminium foil for cucumber cotyledon greening bioassay (Yu et al., 2006; Fletcher et al., 1982).

Cucumber Cotyledons Bioassay for Cytokinins: The method of Fletcher et al., (1981) was used. Cucumber (Cucumus sativus L.) seeds were planted in small poly bags and germinated in the dark at $28^{\circ} \mathrm{C}$. The cotyledons from 7 day old plants were excised in dim green light, making certain that the hypocotyl hook was removed. The cotyledons were placed in $5 \mathrm{~cm}$ Petri dishes containing various concentrations of the eluates from the chromatograms, distilled water and 
kinetin (6-furfuryl-aminopurine). The dishes were returned to the dark at $28^{\circ} \mathrm{C}$ for 24 hours and then exposed to two 1000 watt bulbs in a cupboard. After 3 hours, the cotyledons were homogenized, and the chlorophyll was extracted in $8 \mathrm{ml} 80 \%$ acetone. The volume was brought up to $10 \mathrm{ml}$ with acetone and then centrifuged at 2,500g for 10 minutes. The absorbance of the supernatant were read at 663 and $645 \mathrm{~nm}$. Chlorophyll content was expressed as absorbance at 663nm (Fletcher et al., 1981).

Separation and Quantification of the Cytokinin by High Performance Liquid Chromatography (HPLC): The modified method of Basalah (2001) was adopted. The extract was purified using the Sep Pak $\mathrm{C}_{18}$ cartridge. After the elution of the cytokinins from the cartridge, the eluate was concentrated with the nitrogen stream. The residue was dissolved in the 0.50 $\mathrm{ml}$ of $50 \%$ ethanol and filtered on the column of millipore HV 0.45 micrometers. The concentrated extract injected into the supersphere RP- select B analytical column attached to the waters $600 \mathrm{E}$ Multisolvent Delivery system. Elution was performed with $70 \%$ acetonitrile as solvent $\mathrm{A}$ and $2 \%$ acetic acid as solvent B. The applied flow rate was $0.8 \mathrm{ml}$ per minute at a temperature of $30^{\circ} \mathrm{C}$.

\section{RESULTS AND DISCUSSION}

Cucumber Cotyledons Greening Bioassay for Cytokinin: Cytokinin -like substances obtained from S. stenocarpa were found to induce chlorophyll biosynthesis in cotyledons of dark germinated cucumber seeds. The chlorophyll content was proportionatal to the concentration of the cytokininlike substances in the medium (Figure 1). The results show slight variations to commercial available kinetin.

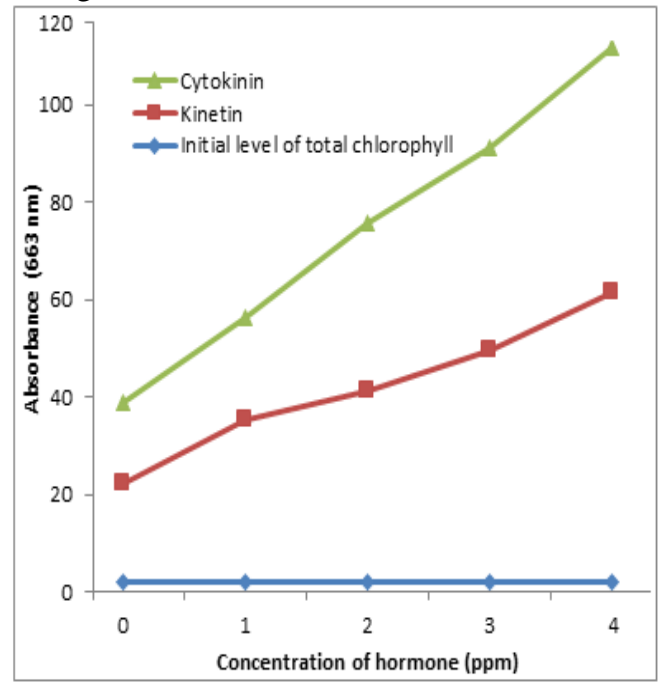

Fig 1: Increase in chlorophyll levels in etiolated cucumber cotyledons treated with various concentrations of cytokinin-like substances and kinetin

Analytical Quantification of Cytokinin fraction by High Performance Liquid Chromatography (HPLC): Cytokinin composition of ungerminated and germinated $S$. stenocarpa seed as determined by High Performance Liquid chromatography is presented in Tables 1 and 2. Identification and quantification of cytokinin fractions are shown in Figures 2 to 7 . Four endogenous cytokinins Zeatin (Z), trans-zeatin (TZ), Isopentenyladenine (iP) and isopentenyladenosine (iPR) were identified and quantified.

Table 1: Cytokinin composition of germinated seed of S. Stenocarpa

\begin{tabular}{lcccc}
\hline Hormone fraction & $\mathrm{Z}$ & $\mathrm{TZ}$ & $\mathrm{IP}$ & 1PR \\
\hline Basic ethyl acetate fraction & 467.14811 & 7.08149 & 7.70569 & 2.51481 \\
Acidic ethyl acetate fraction & 533.10245 & 8.15429 & 1.04392 & 3.43576 \\
n-butanol fraction & 662.77661 & 9.75090 & 1.24620 & 3.90485 \\
Petroleum ether fraction & - & - & - & - \\
N-hexane fraction & - & - & - & - \\
\hline \multicolumn{5}{c}{ Data shown have been computed from Figs. 2-4 }
\end{tabular}

Table 2: Cytokinin composition of ungerminated seed of S. Stenocarpa

\begin{tabular}{lcccc}
\multicolumn{5}{c}{ Table 2: Cytokinin composition of ungerminated seed of S. Stenocarpa } \\
\hline Hormone fraction & $\mathrm{Z}$ & $\mathrm{TZ}$ & $\mathrm{IP}$ & $1 \mathrm{PR}$ \\
\hline Basic ethyl acetate fraction & 1734.43622 & 21.66201 & 1.27199 & 5.69390 \\
Acidic ethyl acetate fraction & 1766.46545 & 22.443521 & 1.31820 & 6.94277 \\
n-butanol fraction & 1960.52480 & 32.53761 & 1.62072 & 9.98202 \\
Petroleum ether fraction & - & - & - & - \\
N-hexane fraction & - & - & - & - \\
\hline een computed from Figs. 5-7 : Key: Z= Zeatin; TZ= Trans-zeatin; IP= Isopentenyl-adenine; IPR = Isopentenyl- \\
adenosine
\end{tabular}

Cytokinin -like substances obtained from Sphenostylis stenocarpa were found to induce chlorophyll biosynthesis in the dark-germinated cotyledons of cucumber. The level of chlorophyll formation was proportional to the concentration of the cytokinin -like substance in the medium. There were slight variations in the results whem compared to the effects of commercially available kinetin. The results obtained during the bioassay with the dark-germinated cotyledons of cucumber showed the presence of cytokinin-like substances in the extracts of $S$. stenocarpa. Previous studies have established that 
cytokinins accelerate chloroplast differentiation (Harvest et al., 1974) as well as regulate and stimulate chlorophyll production in etiolated cucumber cotyledons (Fletcher and McCullagh, 1971; Fletcher et al., 1973). The increase in chlorophyll production was found to be proportional to the concentrations of cytokinin, and this response provides a sensitive, yet rapid, bioassay for cytokinin (Fletcher and McCullagh, 1971).

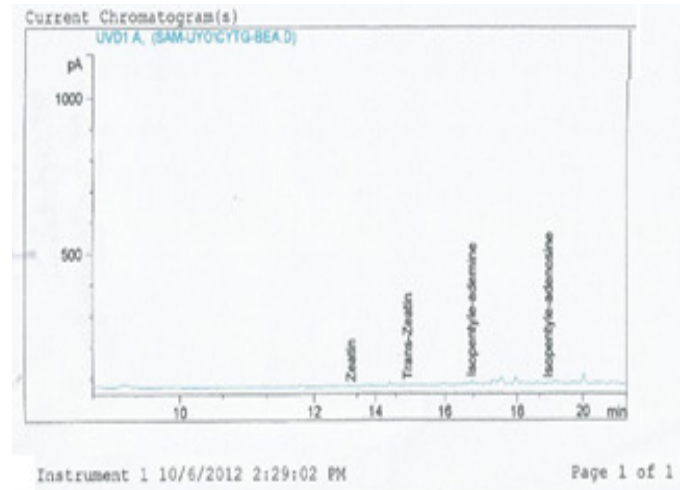

Fig 2: HPLC analysis of basic ethyl acetate fraction of cytokinin in germinated seed of $S$. stenocarpa

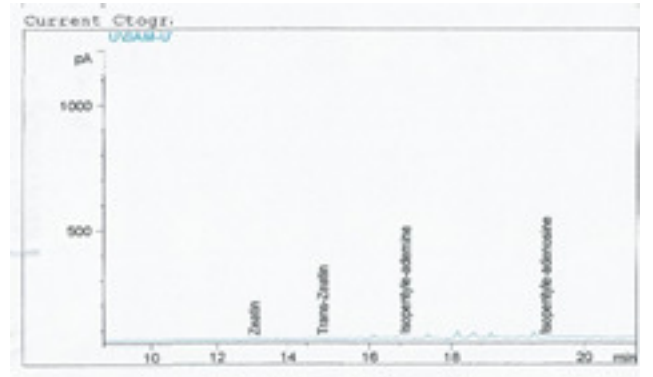

Fig 3: HPLC analysis of n-butanol fraction of cytokinin in germinated seed of S. stenocarpa

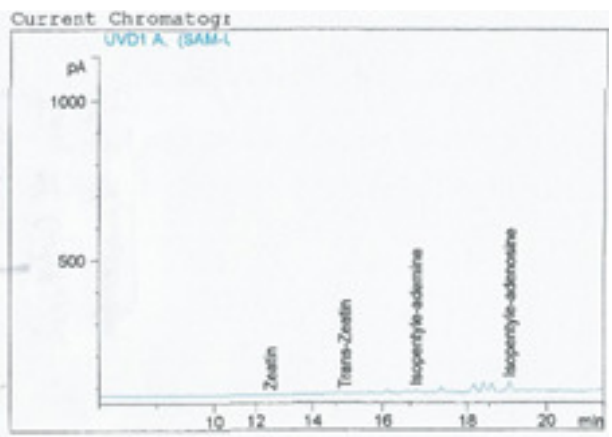

Fig 4: HPLC analysis of acidic ethyl acetate fraction of cytokinin in germinated seed of S. Stenocarpa

The sensitivity and specificity of several cytokinin bioassays, including those based on leaf senescence and callus formation, have been reviewed by Letham (1987). In a comparative study, Dumbroff and Brown
(1976) found that the cucumber cotyledon greening bioassay (Flectcher and McCullagh, 1971) was convenient and sensitive, and it provided a more linear response than did either the oat-leaf yellowing test (Thimann and Sachs, 1966) or the soybean callus test (Miller, 1965). Since then, the cucumber cotyledon assay has been used for studying the effects of herbicides, such as S-ethyl dipropylthiocarbamate, which stimulates (Weinberg and Castelfranco, 1975), and Fluoridone, which inhibits chlorophyll production (Drexler and Fletcher, 1980).

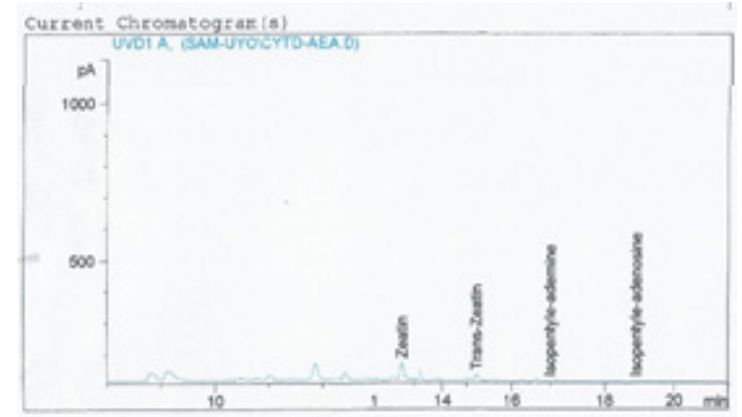

Fig 5: HPLC analysis of acidic ethyl acetate fraction of cytokinin in ungerminated seed of S. stenocarpa

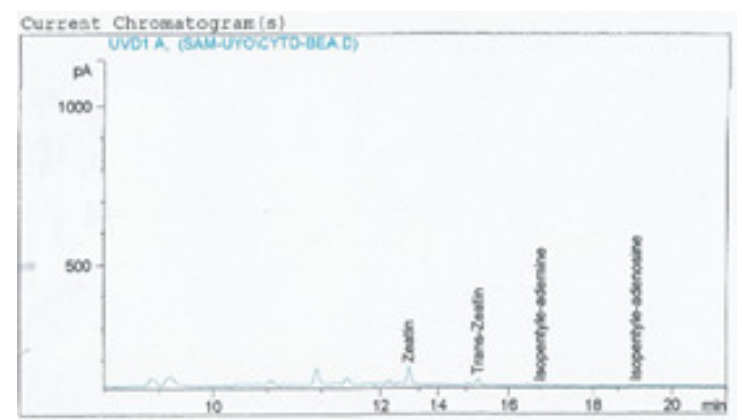

Fig 6: HPLC analysis of basic ethyl acetate fraction of cytokinin in ungerminated seed of S. stenocarpa

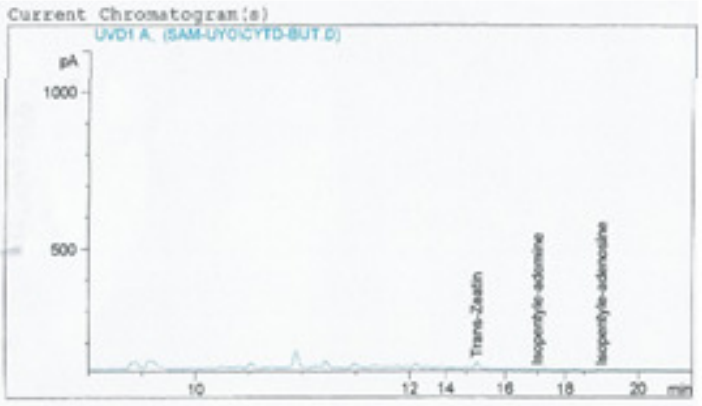

Fig 7: HPLC analysis of n-butanol fraction of cytokinin in ungerminated seed of S. stenocarpa

Brenner et al., (1976) found that the cucumber greening assay (Fletcher and McCullagh, 1971) provided a precise method for cytokinin quantification and identification. This bioassay in conjunction with chemical assays (HPLC) is used routinely for the confirmation of biological activity (Carnes et al., 1973). The amount of chlorophyll produced by 
etiolated cucumber cotyledons after exposure to light is dependent on the age of the cotyledons (Fletcher and Poku, 1976) as well as on the dark incubation period (Dei, 1978). The cucumber greening assay for cytokinins is being used in several laboratories. The cultivar of cucumber does not seem to be an important factor. In this study, the time of exposure to light, temperature at which the seeds are germinated, and the age of the plants (Fletcher and McCullagh, 1971) are important factors in detecting cytokinin concentrations below $1.0 \mathrm{ppm}$. An optimal age of plants for a maximum response to cytokinin was determined. In this study, 7-day-old cotyledons were used. The increase in chlorophyll was found to be proportional to the $\log$ of the concentration of cytokinin. The role of potassium in enhancing the response to cytokinin is not clear. Speculations as to its possible regulatory role as an osmoticum, an ezymes cofactor, or a nonspecific promoter of metabolism are discussed by Green and Murr (1978) and Elliot (1979). The method employed was very simple, quick and inexpensive. The bioassay proved that this product can be used as an alternative to commencial grade kinetin in terms of its ability for chlorophyll biosynthesis. This extract many contain other cytokinin-like substances such as zeatin, 2R-ribosyl zeatin, 2G-glucosyl zeatin etc. (Hutton and Van Staden, 1982). In the cucumber cotyledon greening system, cytokinins eliminate lag phase (Fletcher and McCullagh, 1971b), accelerates chloroplast differentiation and stimulates enzyme activity and chlorophyll production (Harvey et al., 1974).

Conclusion: The amount of chlorophyll produced by etiolated cucumber cotyledons after exposure to light is dependent on the age of the cotyledons as well as on the dark incubation period. In this study, the development of a sensitive and selective method for extraction, identification, characterization and quantifying cytokinins using high performance liquid chromatography (HPLC) has been described.

\section{REFERENCES}

Allen, ON; Allen, EK (1987). The Leguminous. A Source Book of characterization, uses and Nodulation, London: Macmillan Publishers' Ltd p. 620

Basalah, MO (2001). Analysis of Some Plant Growth Regulators in Some Medicinal Dormant Seeds of Desert Plants In Saudi Arabia II: Cytokinin Contents of Citrullus Colocynthis. Park. J. Bio. Sci. 4(3): $341-342$

Benkova, E; Witter, E; Van, DW; Kokar, T; Motyka, V; Brzobohaty, B; Van, OH; Macchackova, I
(1999). Cytokinins in Tobacco and Wheat Chroloplast: Occurrence and Changes due to Light/Dark Treatment. Plant physiol., 121: 245 252

Brenner, ML; Anderson, CR; Cha, AJ; Mondal, M; Brun, W (1976). Relationship of Endogenous Plants Hormone Content to Changes in SourceSink Relationships. In: Pilet, P. E. (Ed.), $9^{\text {th }}$ International Conference on Plant Growth Substances, Laussane, pp 49-50

Carnes, MG; Brenner, ML; Anderson, CR (1973). Rapid Separation an Identification of Plant Growth Substance using High Performance Liquid Chromatography. In: Sumiki, Y. (Ed.), Plant Growth Substances. Tokyo: Hirokawa Publishing Co., pp $99-110$

Dei, M (1978). Inter-organ Control of Greening in Etiolated Cucumber Cotyledons. Plant physiol. 43: $94-98$.

Dewitte, W; Chiappetta, A; Azmi, A; Witter, E; Strnad, M; Rembur, J; Noin, M; Chrigin, D; Van, $\mathrm{OH}$ (1999). Dynamics of Cytokinins in Apical Shoot Meristems of a Day-Neutral Tobacco during Floral Transition and Flower Formation. Plant Physiol. 119: 111- 122

Dumproff, EB; Brown, DC (1976). Cytokinin and Inhibitor Activity Roots and Stems of Sugar Marple Seedling Through the Dormant Season. Canadian J. of Botany, 54: 191 - 197

Elliot, DC (1979). Ionic Regulation for CytokininDependent Betycyanion Synthesis in Amaranthus Seedling. Plant Physiol. 63: $264-268$

Emery, RT; Ma, Q; Atkins, CA (2000). The Forms and Source of Cytokinins in Developing White Lupine Seeds and Fruits. Plant physiol. 123: 1593 - 1604

Ezeagu, IE; Devi, S; Haridas, PR; Nath, H; Rao, AG; Gowda, L; Tarawali, G (2002). Prospects for Incorporation of Defatted Mucuna Flour in Biscuits Formation. J. Food Sci. and Tech., 39: $435-438$

FAO, (2008). Markets, Prices, Food Situation and Prospects for Benin, Niger and Nigeria.http://www.fao.org/docrep/010ai464e/ai4 $\underline{\text { 64eoo.htm }}$

FAO, (1994). The State of Food and Agriculture. FAO Agriculture Series No. 27. FAO, Rome 
Flectcher, RA; Kalllidumbil, V; Steele, P (1982). An Improved Bioassay for Cytokinins using Cucumber Cotyledons. Plants Physiol. 69: 675 677

Fletcher, RA; McCullagh, D (1971b). Benzyladenine as a Regulator of Chlorophyll Synthesis in Cucumber Cotyledons. Canadian J. of Botany, 49: $2197-2201$

Fletcher, RA; McCullagh, D (1971a). Cytikinin Induced Chlorophyll Formation in Cucumber Cotyledons. Planta 101: $88-90$

Fletcher, RA; Poku, JAG (1976). Cytokinins in Relation to Chlorophyll Production in Aging Cucumber Cotyledon. In: Pilet, P. E. (Ed), $9^{\text {th }}$ International Conference on Plant Growth Substances, Lausanne, pp. 98 - 100

Fletcher, RA; Teo, AA (1973). Stimulation of Chlorophyll Synthesis in Cucumber Cotyledons by Benzyladenine. Canadian J. of Botany, 51: 937 939

Green, JF; Muir, RM (1978). The Effect of Potassium on Cotyledon Expansion Induced by Cytokinins. Plant Physiol., 43: 213 - 216

Harvest, B. M. R., Ali, R. C. Fletcher, R. A. (1974). Benzyladenine Accelerates Chloroplast Differentiation and Stimulates Photosynthetic Enzyme Activity in Cucumber Cotyledons. Canadian J. of Botany, 52: 2581 - 2586

Harvey, B. M. R., Lu, B. C. And Fletcher, R. A. (1974). Benzyladenine Accelerates Chloroplast Differentiation and Stimulates Photosynthetic Enzyme Activity in Cucumber Cotyledons. Canadian J. of Botany, 52: 2581 - 2586.

Hoyerova, K; Gaudinova, A; Malbeck, J; Dobrev, PI; Kocabek, T; Solcova, B., Travnickova, A; kaminek; M (2006). Efficiency of Different Mehods of Extraction and Purification of Cytokinins. Phytochem. 67: 1151 - 1159

Hutton, MJ; Van Staden, J (1981). Modification of Brassica Oil Using Conventional and Transgenic Approaches. Annals of Botany, 47: 527

Iqbal, M; Ashraf, M (2005). Presowing Seed Treatment with Cytokinins and its Effect on Growh, Photosynthetic Rate, Ionic Levels and Yield of two Wheat Cultivars Differing in Salt Tolerance. J. of Integrated Plant Biology, 47: 1315 $-1325$
Jacpmard, A; Detry, N; Dewitte, W; Van, OH; Bernier, G (2002). In situ Localization of Cytokinins in the Shootapical Meristem of Sinapsis Alba at Floral Transition. Planta 214: 970 - 973

Jaenicke, HJ; Gemmy, I; Zeledon, H; Kahanne, R (2009). International Symposium on Underutilized Plants for Food Security Nutrition, Income and Sustainable Development. Vol. 2 International Society for Horticultural Science, Arussha, Tanzania.ISBN 9066057017

Klu, GYP; Amoatey, HM; Bansa, D. and Kumaga, FK (2001). Cultivation and Use of African Yam Bean (Sphenostylis stenocarpa) in the Volta Region of Ghana. J. of Food Tech. in Africa, 6 (3): $74-77$

Kudo, T; Kiba, T; Sakakibara H (2010). Metabolism and Long-distance Translocation of Cytokinins. $J$. of Integ.Plant Biology, 52:53 - 60

Letham, DS (1987). Chemistry and Physiology of Kinetin-Like Compounds. Annual Review of Plant Physiol. 18: 349 - 364.

Letham, DS (1994). Cytokinins as Phytohormones: Sites of Biosynthesis, Translocation, and Function of Translocated Cytokinin. CRC, BOCA Raton

Mok, DW; Mok, Mc (2001). Cytokinin Metabolism and Action. Annu. Rev. Plant Physiol. Plant Mol. Biol. 52: $89-118$

Morris, RO; Blevins, DG, Dietrich, JT, Durley, RC; Gelvin, SB; Gray, J. Hommes, NG; Kaminek, M; Mathesius, U; Meilan, R; Reinbott, TM; Sayaredra-Soto, L. (1993). Cytokinins in Plant Pathogenic Bacteria and Developing Cereal Grains. Austral. J. of Plant physiol, 20: 621 - 637

Novak, O; Tarkowski, P; Tarkowka, D; Dolezal, K; Lenobel, R; Strnad, M (2003). Quantitative Analysis of Cytokinins in Plants by Liquid Chromatography- Single-Quadrupole Mass Spectrometry. Analytica Chimica Acta, 480: 207 218

Okigbo, BN (1973). Introducing the Yam Bean (Sphenostylis stenocarpa) (Hochst ex. A. Rich) Harms. In: Processing of the $1^{\text {st }}$ 11TA Grain Legume Improvement Workshop 29 October - 2 November, Ibadan. pp. $224-238$

Parker, CW; Letham, OS (1973). Regulation of Cell Division in Plant Tissues: Metabolism of Zeatin by Radish Cotyledons and Hypocotyls. Planta. 114: $199-218$ 
Porter, D (1992). Economic Botany of Sphenostylis (Leguminosae). Economic Botany, 46 (3): 262-275

Redig, P; Shaul, Inze, D; Van, MM; Yan, OH (1996b). Levels of Endogenous Cytokinins, Indole-3 Acetic Acid and Abscisic Acid during the Cell Cycle of Synchronized Tobacco Br-2 Cells. FEBs Lett 391: 175 - 180

Rice, RF; Rice, LW; Tindall, HD. (1986). Fruits and Vegetables Production in Africa. Hongkong: Macmillan Publishers. India, pp. 264 - 265

Rijavec, T; Kovac, M. Klandnik, A; Choros day PS; DM (2009). A. Comparative study on the role of Cytokinins in Caryopsis Development in the maize miniature 1. Seed Mutant and its Wild Type. J. of Integ. Plants Biology, 51: 840 - 849

Saka, JO; Afibade, SR: Adeniyan, ON. Oluwoyo, RB, and Ogunbodede, BA. (2004). Survey of Underutilized Grain Legume Production Systems in the Southwest Agricultural Zone of Nigeria. Journal of Agricultural and Food Science, 6: 93 108

Sakakibara, H (2006). Cytokinins: Activity Biosynthesis, and Translocation. Annual Review of Plant Biology, 57: 431 - 449

Sakakibara, H; Takai, K (2002). Identification of Cytokinin Biosynthesis Genes in Arabidropsis: a breakthrough for understanding the Metabolic Pathway and the Regulation in higher Plant Growth Regulation, 21: 17 - 23

Samuelson, ME; Larsson, CM (1993). Nitrate Regulation of Zeatin Riboside Levels in Barley Roots: Effects of Inhibitors of $\mathrm{N}$ assimulation and Comparison with Ammonium. Plant Science, 93: $77-84$
Takei, K; Sakakibara, H; Tanuguchi, M; Sugivana, T (2001b), Nitrogen Dependent Accumulation of Cytokinins in Root and the Translocation of Leaf: Implication of Cytokinin Species that Induces Gene Expression of Maize Response Regulator. Plant and Cell Physiol. 42: 85 - 93

Thimann, KV; Sachs, T (1966). The Role of Cytokinins in the Fasciation Disease Caused by Corynebacterium fasciens, American J. of Botany, 52: $731-739$

Weaver, LT (1994). Feeding the Weanling in the Developing World Problems and Solutions. International J. of Food Sci. and Nutr., 45: 127 134

Weinbera, MB; Castelfranco, PA (1975). Effects of EPTC on Plastid Membrane Constitutents in Germinating Cucumber Cotyledons. Weed Science, 3: 185 - 187

Yang, J; Zhang, J; Wang, Z; Zhu, Q. \& Wang, W (2001). Hormonal Changes in the Grains of Rice Subjected to Water Stress During Grain Fitting. Plant Physiol. 127: 315 - 323

Yu, V; Li, G; Xu, D, Dong, X; Qi, X; Deng, Y (2006). An Improvement of Cucumber Cotyledon Greening Bioassay for Cytokinins. Acta Physiologiae Plantarum 28(1): 9- 11

Zhang, S; Li, G; Fang, J; Chen, W; Tiang, H; Zou, J; Liu, Zhao, X; Li, X; Chu, C; Xie, Q; Jiang, X; Zhu, L (2010). The Interactions Among Dwarf 10, Auxin and Cytokinin Underlie Lateral Bud Outgrowth in Rice. J. of Integ. Plant Biol. 52, 626638. 